\title{
Neural adaptations to electrical stimulation strength training
}

\author{
Tibor Hortobágyi • Nicola A. Maffiuletti
}

Received: 11 February 2011/Accepted: 18 May 2011/Published online: 4 June 2011

(C) The Author(s) 2011. This article is published with open access at Springerlink.com

\begin{abstract}
This review provides evidence for the hypothesis that electrostimulation strength training (EST) increases the force of a maximal voluntary contraction (MVC) through neural adaptations in healthy skeletal muscle. Although electrical stimulation and voluntary effort activate muscle differently, there is substantial evidence to suggest that EST modifies the excitability of specific neural paths and such adaptations contribute to the increases in MVC force. Similar to strength training with voluntary contractions, EST increases MVC force after only a few sessions with some changes in muscle biochemistry but without overt muscle hypertrophy. There is some mixed evidence for spinal neural adaptations in the form of an increase in the amplitude of the interpolated twitch and in the amplitude of the volitional wave, with less evidence for changes in spinal excitability. Cross-sectional and exercise studies also suggest that the barrage of sensory and nociceptive inputs acts at the cortical level and can modify the motor cortical output and interhemispheric paths. The data suggest that neural
\end{abstract}

This article is published as part of the Special Issue Cluster on the XVIII Congress of the International Society of Electrophysiology and Kinesiology (ISEK 2010) that took place in Aalborg, Denmark on 16-19 June 2010.

Communicated by Roberto Bottinelli.

T. Hortobágyi $(\square)$

Center for Human Movement Sciences,

University Medical Center Groningen, University of Groningen,

P.O. Box 196, 9700 AD Groningen, The Netherlands

e-mail: Hortobagyit@ecu.edu

\section{N. A. Maffiuletti}

Neuromuscular Research Lab, Schulthess Klinik,

Lengghalde 2, 8008 Zurich, Switzerland

e-mail: Nicola.Maffiuletti@kws.ch adaptations mediate initial increases in MVC force after short-term EST.

Keywords Muscle - Strength training - MRI ·

Magnetic brain stimulation $\cdot$ Rehabilitation

\section{Introduction}

Voluntary strength training (VST) improves the mechanical output of skeletal muscle in healthy humans. Initial increases in force of a maximal voluntary contraction (MVC) are the result of adaptations in the central nervous system (Carroll et al. 2001, 2002; Farthing 2009; Gabriel et al. 2006; Sale 1988; Zhou 2000) although it is now clear that molecular paths associated with muscle growth also become activated after just a few bouts of weight lifting (Costa et al. 2007; Hortobágyi and DeVita 2000; Hortobágyi et al. 2001; Tamaki et al. 2000). Neural adaptations to VST can include spinal (i.e., the motoneuron soma and structures distal to it) or supraspinal adaptations (i.e., structures proximal to the motoneuron soma) (Aagaard et al. 2002; Carroll et al. 2001, 2002, 2011; Christie and Kamen 2010; Del Balso and Cafarelli 2007; Farthing 2009; Gabriel et al. 2006; Gruber et al. 2007; Hortobágyi et al. 2009, 2011; Sale 1988; Taube et al. 2007; Zhou 2000). Hallmarks of supraspinal neural adaptations are the changes in neural drive revealed by increased surface EMG activity during a test MVC, cross education, task specificity, and increases in output of the primary motor cortex and associated cortical areas as measured by electroencephalography (EEG), functional magnetic resonance imaging (fMRI), and transcranial magnetic brain stimulation (TMS). Spinal adaptations can also mediate increases in MVC force and these include changes in motor unit 
activation, motoneuron excitability measured with the $\mathrm{H}$ reflex and voluntary (V) wave, spinal reflex mechanisms such as presynaptic inhibition, reciprocal inhibition, Renshaw inhibition, and synaptic efficiency although some of these measures are not purely spinal as there can be contributions from supraspinal structures.

Similar to VST, EST can also increase voluntary muscle activation as measured with surface electromyography (Maffiuletti et al. 2002), twitch interpolation (Stevens et al. 2004), and the amplitude of the $\mathrm{V}$ wave (Gondin et al. 2006). EST increases MVC force in too short a time for muscle hypertrophy to occur (McMiken et al. 1983). EST also produces voluntary strength gains of the contralateral homologous muscle after unilateral training (Hortobágyi et al. 1999). These observations are consistent with the hypothesis that EST increases MVC force through neural adaptations (Enoka 1988; Lloyd et al. 1986).

However, there are important differences between conditioning skeletal muscle with artificial and voluntary contractions so that the mechanisms cannot be identical. For example, during a voluntary compared with electrical stimulation-evoked contraction motor unit activation is orderly versus non-selective, contraction intensity is high versus submaximal, muscle activation is synergistic versus targeted, antagonist muscle activation is coordinated versus not-coordinated, and the physiological origin of contraction is "internal" versus "external" by activating branches of motor axons under the stimulating electrodes. Despite such differences, and somewhat puzzlingly, EST compared with VST can still produce similar gains in MVC force.

We propose a model in which heightened afferent input associated with electrical muscle stimulation plays a key role in neural adaptations to EST (Fig. 1). Because peripheral sensory nerves have a lower threshold of excitability compared with the sarcolemma surrounding muscle fibers, electrical muscle stimulation, as commonly used in EST, produces a barrage of cutaneous and nociceptive input. This heightened sensory information reaches the sensorimotor cortex and provides input to motor areas in the brain, giving rise to volleys that descend in corticospinal and motor neurons, causing muscle to contract. In addition to this afferent-invoked drive, the induction current directly excites and contracts superficial muscle fibers. Although EST can evoke changes in specific measures of spinal cord function, there is less evidence for changes in spinal excitability. In contrast, during VST, the descending command gives rise to the muscle fiber contraction and the voluntary effort uses proprioceptive afferent information as a feedback and not as a driver of muscle contraction, as proposed for EST.

The present paper evaluates this model in terms of neural adaptations at the spinal and supraspinal levels. We review the mechanisms of neural adaptations to EST rather than comparing the changes in MVC force after EST and VST, an approach used previously (Bax et al. 2005; Maffiuletti 2010). To more precisely isolate the effects produced by unadulterated electrical stimulation we did not explicitly review studies that delivered the training stimulus in the form of electrical stimulation superimposed on voluntary muscle contraction, so-called hybrid training (Bezerra et al. 2009; Langzam et al. 2006, 2007; Paillard et al. 2005, 2010). To concentrate the review on muscle instead of nerve stimulation, we included only two studies that reported on the effects of direct electrical stimulation of a peripheral nerve on motor output (Everaert et al. 2010; Stein et al. 2010). The review focuses on healthy muscles and incorporated only a handful of studies that used EST or functional electrical stimulation (FES) of impaired muscles. Because the evidence was scant or inconclusive we did not review all of the possible neural adaptation mechanisms in detail, including the rate of voluntary force development, antagonist muscle coactivation, and single motor unit studies. Therefore, the purpose was to review evidence for supraspinal and spinal adaptations associated with EST in healthy human skeletal muscle.

\section{Spinal adaptations}

Increase in MVC force in the absence of muscle hypertrophy

A series of EST studies suggest that neural adaptations mediate increases in MVC force because the increases in force occur without significant muscle hypertrophy (Brocherie et al. 2005; McMiken et al. 1983; Pichon et al. 1995). Although none of these studies measured directly muscle size before and after the training program, the brevity of the protocols, which sharply contrasts with early studies using extreme stimulation conditions that are not adaptable to clinical settings (e.g., stimulation for $3 \mathrm{~h}$ per day, 6 days a week for 6 weeks, Rutherford, 1988) (Jarvis et al. 1996; Pette and Vrbova 1992; Schiaffino et al. 1989; Scott et al. 1985), and the advanced athletic status of the participants indirectly suggest neural and not muscle adaptations are the core moderators of increases in MVC force. For example, after 3 weeks of EST, isokinetic eccentric and concentric torque increased significantly in nine ice-hockey players whose 10 and $30 \mathrm{~m}$ sprint skating times also improved (Brocherie et al. 2005). Likewise, EST of the latissimus dorsi increased the strength and swimming performances of a group of competitive swimmers (Pichon et al. 1995). These data must be interpreted cautiously because of a lack of direct measurement of muscle fiber size. However, results from studies that did directly measure changes in muscle fiber size, reviewed next, are 


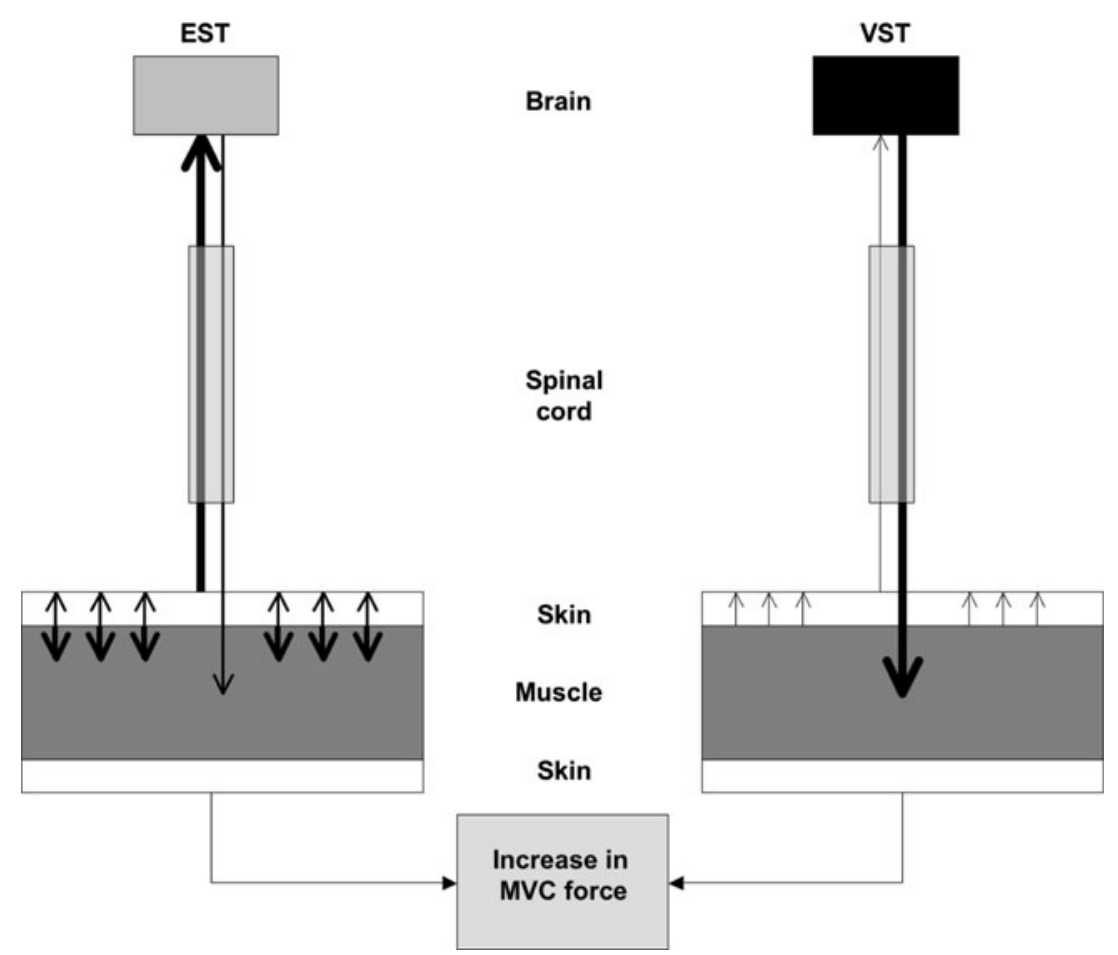

Fig. 1 Conceptual model comparing sources of neural adaptations during electrical stimulation strength training (EST) and voluntary strength training (VST). After EST (left side), an increase in MVC force is the result of a barrage of ascending afferent input to sensorimotor cortical areas, impinging on descending motor paths. The thick upward pointing arrow is the result of electrical muscle stimulation exciting afferents (short thin upward pointing arrows), representing a strong component of neural adaptations in response to EST. Induction currents generated inside the muscle by electrical

still compatible with the idea that neural adaptations contributed to the gains in motor performance.

Although there are numerous studies that reported changes in muscle metabolism, none provide compelling evidence that EST, similar to the paradigms used in clinical settings, produces early muscle hypertrophy (i.e., in less than 6 weeks). While there were significant increases in quadriceps MVC force from $1,295 \mathrm{~N}( \pm 135)$ to $1,530 \mathrm{~N}$ $( \pm 131)$ after a 4 week training period in one study that used 6 min effective EST in each of 15 sessions, these changes were similar to the gains produced by VST without significant changes in enzyme activities, muscle fiber characteristics, or mitochondrial properties (Eriksson et al. 1981; Kim et al. 1995; Martin et al. 1993, 1994; St Pierre et al. 1986). Twenty-one days of EST of the gastrocnemius muscle reduced skinfold thickness by $20 \%$ and it increased MVC force by $42 \%$, nuclear number per unit area by $37 \%$, mean length of muscle cell nuclei by $14 \%$, and nuclear density by $21 \%$ (all $p<0.05$ ), muscle fiber size increased moderately $(16 \%, p<0.05)$ in the $50 \mathrm{~Hz}$ stimulation group and by $10 \%(p>0.05)$ in the $2,000 \mathrm{~Hz}$ stimulation group (Cabric and Appell 1987; Cabric et al. 1987). A study using muscle stimulation (short downward pointing arrows), represent direct sarcolemmal depolarization and muscle contraction. In contrast, VST has much smaller ascending afferent input to sensory areas but large descending volleys that generate voluntary drive and MVC force. EST and VST can produce similar increases in MVC force but through different mechanisms. Thicker arrows and darker colors represent an enhanced effect. For the sake of simplicity, other brain areas activated during an electrical stimulation-evoked and a voluntary contraction are not shown

nuclear magnetic resonance spectroscopy after 13-15 $\mathrm{min}$ of low-intensity (10\% MVC) voluntary or electrical stimulation-evoked contractions of the gastrocnemius revealed that the muscle was more acidic and the muscle cytoplasm was more oxygenated during stimulated than voluntary exercise, suggesting higher levels of glycolysis and oxygen demand (Vanderthommen et al. 2003). Thus, the data confirmed that electrical muscle stimulation is fatiguing but there was no hint for changes in metabolic pathways linked to muscle hypertrophy. Six weeks of quadriceps EST at $8 \mathrm{~Hz}$, a rate lower than most EST studies, in 20 sedentary, 10 active, and five endurance-trained subjects using 25 consecutive $10 \mathrm{~s}$ isometric contractions increased citrate synthase activity, capillary number per type IIA and IIB fibers, and the percentage of type IIA muscle fibers but, again, failed to increase the size of type I, IIA, and IIB muscle fibers (Theriault et al. 1996). In an EST study similar to the protocols most often used in clinical settings to strengthen healthy and an orthopedic injury-weakened muscle (Bax et al. 2005), vastus lateralis biopsy samples from ten healthy volunteers who received EST at $45-60 \mathrm{~Hz}$, with $12 \mathrm{~s}$ of stimulation followed by $8 \mathrm{~s}$ of rest 
for a total of $30 \mathrm{~min}$ per day, 3 days/week for 6 weeks revealed an increased expression of $\mathrm{MHC}$ isoform IIA through a shift of MHC-I and MHC-IIX isoforms to the MHC-IIA isoform (Perez et al. 2002), but these fiber type conversions occurred without muscle fiber hypertrophy. Unlike in previous studies (Brocherie et al. 2005; McMiken et al. 1983; Pichon et al. 1995), these EST-induced shifts in the biochemical characteristics were not associated with improvements in whole-body aerobic performance or neuromuscular function produced by muscles of the entire limb (Perez et al. 2002). EST over an initial 4 week period failed to increase quadriceps size measured with ultrasound, but muscle size did increase a modest $4 \%( \pm 2$, $p<0.001$ ) from week 4 to 8 (Gondin et al. 2005) and increased up to $12 \%$ after 8-9 weeks (Gondin et al. 2011; Ruther et al. 1995; Stevenson and Dudley 2001), suggesting muscle hypertrophy occurred in the late phase of the program. Taken together, these results suggest that EST administered with a clinical dose and parameters for up to about 6 weeks does bring about changes in muscle metabolism and promotes subtle isoform shifts, but the increased MVC force is not the result of overt muscle hypertrophy, but instead, it is mediated by changes in some elements of the nervous system. Therefore, these studies seem to support the idea that short-term EST increases MVC force through neural mechanisms.

\section{Muscle activation}

The time course of adaptation to VST and EST seems to be strikingly similar, suggesting that muscle activation is probably also rising in step with MVC force. For example, when VST and EST groups were matched for training intensity (Hortobágyi et al. 1998; Lieber et al. 1996), both interventions increased MVC force at the same rate and time course. Recent studies confirm this observation and suggest that as MVC force increases muscle activation also increases from the initial 80-90\% level in most (Gondin et al. 2005; Jubeau et al. 2006; Maffiuletti et al. 2002; Stevens et al. 2004) but not all cases (Colson et al. 2009), followed by muscle hypertrophy (Gondin et al. 2005) (but see section "Increase in MVC force in the absence of muscle hypertrophy"). However, what appears as a straightforward issue, i.e., increased muscle activation, as a neural mechanism mediating strength gains after EST, is a more complex issue.

A change in muscle activation is a measure of neural adaptation after VST and EST. A crude index of muscle activation is the change in surface EMG activity measured during a test MVC contraction before and after the intervention, with an increase in EMG activity being the summed expression of increased muscle activation caused by an increase in discharge rate of motor units and/or their spatial recruitment. Because acquiring surface EMG data before and after electrical stimulation interventions is technically relatively uncomplicated, this method has been intensely used despite criticisms from modeling studies, suggesting that signal cancelation and other technical details can substantially undermine the interpretation of such changes in EMG activity after an intervention (Farina et al. 2010). To illustrate, one study actually reported a decrease in EMG activity with increased MVC force after voluntary training (Thorstensson et al. 1976). Furthermore, in a recent study there were no changes in M-wave-normalized surface EMG activity following EST of an arm muscle (Colson et al. 2009), whereas other studies in leg muscles did show increases in EMG activity recorded during a test MVC after EST (Gondin et al. 2005; Maffiuletti et al. 2002), making it difficult to draw any definitive conclusions whether changes in EMG activation after EST is or is not a valid indicator of neural adaptations.

Maximal tetanic stimulation (Sale 1988), twitch interpolation (Merton 1954), including its permutation as central activation ratio (Kent-Braun and Le Blanc 1996), and muscle stimulation-evoked contraction in the relaxed or concurrently contracted muscle (Hortobágyi et al. 1998) are presumably more precise measures of muscle activation. Maximal tetanic stimulation was implemented in several studies targeting small hand muscles (see a list of references in Sale 1988) and because, as expected, untrained healthy individuals can activate these muscles fully maximal tetanic stimulation revealed no changes in muscle activation after strength training (Sale 1988). Indeed, authors of one study concluded that "...electrostimulation augments the muscle force of contraction by changing peripheral processes associated with intra-cellular events, without modifying the nervous command of the contraction" (page 99 in Duchateau and Hainaut 1988). Most likely due to the disruptive discomfort, there are no studies that compared maximal tetanic forces in large postural muscles before and after voluntary and EST.

Over 20 authors debated recently whether the twitch interpolation is or is not a valid method of assessing muscle activation (de Haan et al. 2009; Taylor 2009). Because many EST studies use lower limb muscles as a model, the relevant conclusion of a review is as follows: "...studies using stimulation methods support the conclusion that both elderly and young subjects are able to fully activate their distal lower limb muscles during concentric and eccentric contractions performed at angular velocities up to $240 \%$ s" (page 547 in Klass et al. 2007).

If there is this much controversy and debate concerning the validity of this technique concerning neural adaptations after VST, these difficulties are further compounded under the conditions of EST due to the differences in motor unit activation between voluntary versus stimulation-evoked 
contractions. Although the order of motor unit recruitment is probably not reversed relative to the size principle during electrical stimulation-evoked contractions, there are still many details of motor unit recruitment that differ between force production with a voluntary effort and electrical stimulation, including order, temporal, and spatial aspects of motor unit recruitment (see the "discussion" in this issue Bergquist et al. 2011) and (Enoka 2006; Fitzgerald and Delitto 2006; Gregory and Bickel 2005; Jubeau et al. 2010; Maffiuletti 2010). Therefore, how comparable twitch interpolation results are to assess neural adaptations after VST and EST is unclear. To illustrate, a recent crosssectional study reported that quadriceps activation was significantly lower during electrical stimulation-evoked compared with voluntary contraction at the same absolute submaximal force level up to $60 \%$ MVC (Jubeau et al. 2010). If this is the case, then twitch interpolation is expected to predict different magnitudes of neural adaptation after the two training modes, larger after EST. In addition, an imaging study, omitted from the twitch-interpolation debate (de Haan et al. 2009; Taylor 2009), also provided evidence that electrical muscle stimulation recruited only $75 \%( \pm 14, n=7)$ of the quadriceps femoris volume when the muscle activation was well over $90 \%$, implying a substantial underestimation of muscle activation by twitch interpolation (Kendall et al. 2006), at least in the large quadriceps muscle. This study suggests that during electrical stimulation of the quadriceps muscle, the current reaches only a fraction of the available muscle volume. A part of neural adaptation comes from subjects' increased pain tolerance that permits the delivery of higher and higher stimulation current, hence increasing muscle mass recruitment. Indeed, contrary to previous suggestions (Fitzgerald and Delitto 2006), a previous study did find that six of eight healthy female volunteers were able to produce greater electrical stimulation-evoked than MVC force following EST, suggesting that quadriceps muscle activation after EST was incomplete (Hortobágyi et al. 1998).

In total, EST increases MVC force but it is inconclusive whether the increase in muscle activation as measured with twitch interpolation is related to the increase in the MVC force because EST may recruit a different population of muscle fibers compared with the population assessed with twitch interpolation. Although dependent on subjects' pain tolerance, evoking maximal force with electrical stimulation before and after EST would increase the specificity of testing the training adaptations and reduce potential inaccuracies associated with twitch interpolation. Therefore, future studies will have to determine critical details concerning the volume of muscle activated during voluntary force production, electrical stimulation-evoked contractions, and twitch interpolation. To get a more realistic picture on the role of motor unit activation plays in EST-evoked neural adaptations, twitch interpolation will have to be implemented during test MVCs and also during electrical stimulation-evoked contractions (Jubeau et al. 2010).

\section{Spinal excitability}

The Hoffmann or $\mathrm{H}$ reflex has been extensively used as a gauge of plasticity in the human nervous system in response to exercise training or other interventions (Zehr 2002). VST produced mixed results in terms of spinal plasticity, a form of neural adaptation. While in a few studies spinal excitability increased in a coupled fashion with MVC force (Del Balso and Cafarelli 2007; Dragert and Zehr 2011; Duclay et al. 2008; Fimland et al. 2009), other studies reported an increase in MVC force after VST without changes in spinal excitability (Aagaard et al. 2002; Dragert and Zehr 2011; Duclay et al. 2008; Scaglioni et al. 2002). In one study the $H$ reflex amplitude measured on the ascending limb of the recruitment curve increased but the amplitude of the maximal $\mathrm{H}$ reflex did not change in the resistance-trained plantarflexors (Lagerquist et al. 2006). In addition, endurance training and two-legged hopping also increased spinal excitability (Perot et al. 1991; Voigt et al. 1998). It should be noted that all of these studies were conducted in lower extremity muscles, and it is unknown if the responses would follow a similarly inconsistent pattern in muscles of the upper extremity in which the $\mathrm{H}$ reflex can be measured relatively easily (e.g. wrist flexors and extensors).

Chronic artificial neural activation produces remarkable and long-lasting spinal plasticity in animal models (Chen et al. 2010; Wolpaw 2007). Experiments in humans and in the cat suggest that electrical stimulation of cutaneous afferents in the sole of the foot or digital nerves of the hand increases the excitability of the Ib pathway (Arya et al. 1991; Cavallari et al. 1985; Pierrot-Deseilligny et al. 1981) and have, in general, an excitatory effect on homologous motoneuron pool (Pierrot-Deseilligny et al. 1973; Robinson et al. 1979). Therefore, it is conceivable that EST would invoke neural adaptations and contribute to the increased MVC force through an increase in spinal excitability as measured with the $\mathrm{H}$ reflex and its different variants.

Contrary to this prediction, the limited amount of information available to date on the effects of EST on spinal excitability suggests little or no adaptations in this mechanism. For example, in one study subjects completed 16 sessions of isometric EST at $75 \mathrm{~Hz}$ over a 4-week period but no significant changes occurred in the maximal amplitude of the $\mathrm{M}$ wave, $\mathrm{H}$ reflex, and the tendon tap reflex evoked in the resting soleus and gastrocnemius of eight volunteers (Maffiuletti et al. 2003). In another study, 
4 weeks of EST of the plantarflexors increased MVC force by $19 \%$, but there were, again, no changes in the maximal amplitude of the $\mathrm{M}$ wave and the $\mathrm{H}$ reflex evoked at rest although there were increases in reflex amplitude after additional 4 weeks of detraining (Jubeau et al. 2006). Electrical stimulation at an intensity evoking tingling sensation without a muscle contraction acutely reduced the time to peak of the H-reflex-evoked twitch responses (Trimble and Enoka 1991). Because H reflexes selectively excite low-threshold motor units, sensory (sub-motor threshold) electrical stimulation must have activated fastercontracting motor units in the responses to the H-reflex stimulus (Trimble and Enoka 1991). Although this study reported the mechanical responses to $\mathrm{H}$ reflex stimulation but not the reflex amplitude, the data still suggest that under certain conditions EST could produce adaptations in spinal excitability. However, the bulk of the data suggests that the EST-evoked adaptations, as measured with the $\mathrm{H}$ reflex, are small. Perhaps the parameters of EST (duration, intensity) were insufficient to cause changes in spinal mechanisms. Indeed, an accompanying article in this series (Bergquist et al. 2011) presents in detail how an increase in electrical stimulation pulse width to $1 \mathrm{~ms}$ increased the sensory feedback to the muscle and increased the magnitude of force evoked (Collins et al. 2002). Briefly, electrical muscle stimulation at $100 \mathrm{~Hz}$ and $1 \mathrm{~ms}$ pulse width compared with stimulation at $25 \mathrm{~Hz}$ with $0.05 \mathrm{~ms}$ pulse width produced significantly greater torque and this torque enhancement was attributed to spinal mechanism invoked by the greater sensory input to the muscle. In follow-up experiments an anesthetic block of the peripheral nerves proximal to the stimulation site prevented the afferent flow to the central nervous system, confirming the central origin of the enhanced mechanical output produced by the wider pulse-width paradigm (Collins 2007).

The implications of these findings for neural adaptation to EST are that because the afferent feedback and the direct stimulation of the nerve branches activate different motor units so that EST with wide-pulse stimulation may bring about increases in voluntary force with less fatigue (Baldwin et al. 2006; Klakowicz et al. 2006). Thus, stimulation parameters can be important determinants of the magnitude and locus of EST-evoked adaptations. In addition to varying stimulation parameters, there is also a need to increase the versatility of measurement techniques, including the use of $\mathrm{H}$ reflex and $\mathrm{V}$ waves that are evoked during a voluntary muscle contraction (Gondin et al. 2006) and, although technically challenging, $\mathrm{H}$ reflexes and $\mathrm{V}$ waves measured during electrical stimulation-evoked muscle contractions to increase the specificity of assessing the changes in spinal excitability. All in all, these observations shift the locus of neural adaptation from spinal to supraspinal mechanisms.

\section{Supraspinal adaptations}

Brain activation

Conventional views somewhat naïvely maintained that electrical muscle stimulation has a negligible effect on supraspinal structures and that mostly spinal mechanisms mediate the EST-evoked gains in MVC force. However, behavioral, fMRI, and TMS studies provide strong evidence that increased somatosensory input may actually cause cortical organization (Kimberley et al. 2004; Nudo et al. 2001). Thus, EST has a substantial potential to invoke neural adaptations through cortical plasticity. Electrical muscle stimulation excites axons of sensory receptors, and these action potentials ascend via afferent paths to the primary somatosensory cortex, providing a basis for the contribution of afferent input to neural adaptation after EST (Fig. 1).

The behavioral manifestation of afferent input was apparent in a study in which maximal tolerable electrical muscle stimulation was applied to the right quadriceps at rest while sedentary individuals and weight lifters contracted the left quadriceps. Compared with no stimulation, electrical stimulation of the right quadriceps increased MVC force on the left side by 16 and $6 \%$ in the untrained and trained subjects, respectively (Howard and Enoka 1991). These significant increases in MVC force were probably due to the electrical stimulation-generated sensory effects that cortically or spinally enhanced the motor output from the contracting muscle.

There are multiple lines of evidence from imaging studies, suggesting that electrical muscle stimulation activates sensory and motor cortical areas in the healthy human brain. We must emphasize that most of these studies are cross-sectional and did not directly assess neural adaptations to EST. In one fMRI study monophasic square wave pulses were delivered at $30 \mathrm{~Hz}$, with a pulse width of $200 \mu$ s and a $1 \mathrm{~s}$ on-and-off cycle for six, 20-s-long epochs alternating between rest and electrical stimulation of the wrist extensor muscles. Electrical stimulation increased the activation of the primary sensorimotor cortex contralateral to the side of stimulation and it also produced bilateral activation of the supplementary motor areas (Han et al. 2003). The analysis in this study was restricted to the primary motor and sensory cortices, premotor, and supplementary motor areas (Han et al. 2003). In a more detailed experiment, healthy volunteers' wrist extensor and flexor muscles were stimulated with 1-s-long, asymmetric, biphasic, $200 \mu$ s-wide FES at $20 \mathrm{~Hz}$, producing 22 contractions separated by 17-22 s of rest (Blickenstorfer et al. 2009). fMRI data revealed significant activation of the contralateral primary motor cortex, primary somatosensory cortex and premotor cortex, the ipsilateral cerebellum, 
bilateral secondary somatosensory cortex, the supplementary motor area, and anterior cingulate cortex (Blickenstorfer et al. 2009). These results obtained with FES compare surprisingly well with brain activation data from another fMRI study that also reported a dose-response relationship between the intensity of lower extremity electrical muscle stimulation and activation of specific brain regions (Smith et al. 2003).

As in any electrical muscle stimulation study, it is hard if not impossible to tell if participants, against instructions, do not, in addition to electrical muscle stimulation, voluntarily contract their muscles. Assuming that no such incidental contractions occurred in these experiments, it is an important observation that electrical muscle stimulation and FES activated cortical areas that are involved not only in sensation but also in planning and generating motor output. These are the same areas that voluntary movement and, to a smaller extent, passive movements also activate. Therefore, EST and FES training seem to have the potential to produce some elementary motor learning or at least not to interfere with coordinated movement. Indeed, one of the strongest pieces of evidence for EST to produce strength and skill effects comes from gait re-training studies (Everaert et al. 2010; Stein et al. 2010). Stroke $(n=10)$ and multiple sclerosis patients $(n=26)$ used a foot-drop stimulator for 3-12 months while freely ambulating. Although the nature of this FES modality was far from the maximal electrical stimulation-evoked contractions, TMS-generated motor evoked potentials in the tibialis anterior increased $\sim 50 \%$ in stroke and also in multiple sclerosis patients and MVC force increased, respectively, 27 and $17 \%$ in the two groups. Stroke patients' walking speed increased by $24 \%$ with the stimulator off (therapeutic effect) and by $7 \%$ in the other patient group. The correlated increases in motor-evoked potentials and MVC force suggest that EST increased the output from motor cortical areas and the functional excitability of the descending paths involved in the control of the tibialis anterior (Everaert et al. 2010). These studies provide strong evidence for the hypothesis and for our model (Fig. 1) that somatosensory and nociceptive inputs lead to changes in motor cortical excitability, which in turn can cause functional improvements, including muscle strength and coordination (Francis et al. 2009; Kaelin-Lang et al. 2002; Khaslavskaia and Sinkjaer 2005; Ogino et al. 2002; Ridding et al. 2000, 2001. However, future studies must specifically address the issue if EST causes similar plastic changes in motor cortical output of healthy individuals and patients recovering from muscle weakness, and how such changes relate to the increased MVC force. This is especially necessary because it is now believed that FES-therapy should start with an EST program, creating a sequential link between the two forms of therapies practiced most often independently (Popovic et al. 2001; Smith et al. 2003).

In total, there is an abundance of evidence to suggest that electrical muscle stimulation activates sensory and motor cortices. There is a need to conduct imaging and TMS studies to provide direct evidence whether EST causes plastic changes in the central nervous system and whether such changes are associated with the increase in MVC force.

\section{Cross education}

Perhaps the strongest evidence for neural adaptations associated with EST is the increase in MVC force in the untrained, homologous muscle of the contralateral limb after unilateral EST. Cross-sectional experiments revealed that electrical muscle stimulation compared with voluntary contraction evokes different supraspinal effects even though EST and VST can both increase MVC force (Bezerra et al. 2009; Farthing 2009; Hortobágyi et al. 1999; Zhou 2000). While healthy volunteers contracted the left wrist flexors isometrically, the amplitude of the motor potentials evoked by TMS increased and the amplitude of the $\mathrm{H}$ reflex decreased in the homologous, right wrist flexors (Hortobágyi et al. 2003). In contrast, when electrical muscle stimulation was used to evoke left wrist flexion, the motor-evoked potentials and $\mathrm{H}$ reflex both increased in the right wrist flexors. Superimposition of electrical muscle stimulation on a voluntary contraction of the left wrist flexors, again, increased the TMS response and decreased the $\mathrm{H}$ reflex in the right, resting wrist flexors. These observations suggest that electrical muscle stimulation and voluntary contraction have different supraspinal effects in the contralateral homologous muscle. Indeed, 6 weeks of EST with eccentric contraction of the right quadriceps muscle produced over $60 \%$ increase in MVC force of the untrained, left quadriceps muscle in healthy young adults (Hortobágyi et al. 1999). EST was also more effective than VST in producing cross education without signs for muscle hypertrophy (Bezerra et al. 2009), producing over 30\% cross education independent of electrical muscle stimulation frequency (Cabric and Appell 1987). Finally, unilateral electroacupuncture administered to the right tibialis anterior muscle of healthy adults with a stimulation frequency of $40 \mathrm{~Hz}$, a pulse-width of $1 \mathrm{~ms}$, an intensity of $30-40 \mathrm{~V}$, using eight duty cycles of $1 \mathrm{~min}$ on and $1 \mathrm{~min}$ off increased MVC force $21 \%$ in the intervention and also in the resting, non-intervention left leg 15\% (Huang et al. 2007).

The picture emerging from these studies suggests that EST is capable of modifying the excitability of interhemispheric connections and perhaps the balance between interhemispheric excitation and inhibition. Indeed, when 
Table 1 Summary of neural adaptations induced by electrical stimulation strength training in healthy human skeletal muscle

\begin{tabular}{lr}
\hline Magnitude of contribution & \\
\hline Spinal & \pm \\
Neural drive (change in EMG) & \pm \\
Muscle activation & - \\
Spinal excitability & \pm \\
Presynaptic inhibition & \pm \\
Reciprocal inhibition & \pm \\
Renshaw inhibition & \pm \\
Synaptic efficacy & \\
Supraspinal & + \\
Cross education & + \\
Task specificity & + \\
Sensory cortex activation & \\
\hline
\end{tabular}

+ strong, \pm unclear, - low

repetitive TMS created a virtual lesion in the exercising brain, the magnitude of cross transfer of ballistic performance learned in one hand was acutely reduced in the nonpracticed hand in one session, suggesting that cortical processes within the untrained hemisphere must have contributed to the crossed effects (Lee et al. 2010). Recent chronic VST studies using TMS and fMRI confirmed that reduced interhemispheric inhibition and increased activation of specific areas in the non-exercised brain are key moderators of cross education in healthy adults (Farthing et al. 2011; Hortobágyi et al. 2011). Additional studies are needed to determine whether EST-induced increases in MVC force are mediated by the same supraspinal and spinal mechanisms in healthy humans (Aagaard et al. 2002; Dragert and Zehr 2011; Fimland et al. 2009).

\section{Summary and future directions}

A review of the data confirms the hypothesis that in the early phases of EST, like VST, increases in MVC force occur through neural mechanisms without muscle hypertrophy in healthy young adults (Fig. 1; Table 1). Although, in several EST studies the stimulation-evoked contractions were much weaker than the contraction intensity used in VST, still, somewhat puzzlingly, gains in MVC force were similar. Increases in MVC force occurred in the absence of muscle hypertrophy. This review found weak support for the involvement of a spinal mechanism to mediate increases in MVC force after EST (Table 1). There is strong evidence to suggest that acute bouts of electrical muscle stimulation may activate sensory, sensorimotor, and motor areas and possibly interhemispheric paths in the brain. Cross-sectional studies suggest that the potential is high for supraspinal adaptations to occur after EST but there are yet no chronic MRI, TMS, and EEG studies that document supraspinal adaptations subsequent to EST. There is also a need for more detailed information on spinal excitability changes instead of just using a single measure such as H reflex amplitude (Dragert and Zehr 2011). To determine the net effect due to sensory input associated with EST, there is a need to incorporate in the experimental design a group that receives sham stimulation (Glinsky et al. 2009; Golaszewski et al. 2010; Nuhr et al. 2003; Smith et al. 2003) or stimulation that is remotely relative to the target muscle (Hortobágyi et al. 1999). There is a need to conduct placebo-controlled trials in which electrical muscle stimulation is replaced with a non-electrical agent to better understand the placebo effects of EST on MVC force. Unlike many previous studies, future EST studies should measure not only MVC force but also electrical muscle stimulation-evoked forces to gain more precise insights into the task-specificity of EST. Finally, the ultimate goal is to understand neural and muscular adaptations to EST in healthy individuals so that the findings can be safely extended to treating patients' clinical conditions. EST is particularly useful to preserve muscle mass during prolonged periods of partial/total immobilization, as it is the case with patients in an intensive care unit, or who suffer from chronic heart failure, chronic obstructive pulmonary disease, or a stroke.

Acknowledgments We thank Paul DeVita, PhD and Jean Lambert, $\mathrm{PT}, \mathrm{PhD}$ for their insightful comments.

Open Access This article is distributed under the terms of the Creative Commons Attribution Noncommercial License which permits any noncommercial use, distribution, and reproduction in any medium, provided the original author(s) and source are credited.

\section{References}

Aagaard P, Simonsen EB, Andersen JL, Magnusson P, Dyhre-Poulsen $P$ (2002) Neural adaptation to resistance training: changes in evoked V-wave and H-reflex responses. J Appl Physiol 92:2309-2318

Arya T, Bajwa S, Edgley SA (1991) Crossed reflex actions from group II muscle afferents in the lumbar spinal cord of the anaesthetized cat. J Physiol 444:117-131

Baldwin ER, Klakowicz PM, Collins DF (2006) Wide-pulse-width, high-frequency neuromuscular stimulation: implications for functional electrical stimulation. J Appl Physiol 101:228-240

Bax L, Staes F, Verhagen A (2005) Does neuromuscular electrical stimulation strengthen the quadriceps femoris? A systematic review of randomised controlled trials. Sports Med 35:191-212

Bergquist AJ, Clair JM, Lagerquist O, Mang CS, Okuma Y, Collins DF (2011) Neuromuscular electrical stimulation: implications of the electrically-evoked sensory volley. Eur J Appl Physiol (in press) 
Bezerra P, Zhou S, Crowley Z, Brooks L, Hooper A (2009) Effects of unilateral electromyostimulation superimposed on voluntary training on strength and cross-sectional area. Muscle Nerve 40:430-437

Blickenstorfer A, Kleiser R, Keller T, Keisker B, Meyer M, Riener R, Kollias S (2009) Cortical and subcortical correlates of functional electrical stimulation of wrist extensor and flexor muscles revealed by fMRI. Hum Brain Mapp 30:963-975

Brocherie F, Babault N, Cometti G, Maffiuletti N, Chatard JC (2005) Electrostimulation training effects on the physical performance of ice hockey players. Med Sci Sports Exerc 37:455-460

Cabric M, Appell HJ (1987) Effect of electrical stimulation of high and low frequency on maximum isometric force and some morphological characteristics in men. Int $\mathrm{J}$ Sports Med 8:256-260

Cabric M, Appell HJ, Resic A (1987) Effects of electrical stimulation of different frequencies on the myonuclei and fiber size in human muscle. Int J Sports Med 8:323-326

Carroll TJ, Riek S, Carson RG (2001) Neural adaptations to resistance training: implications for movement control. Sports Med 31:829-840

Carroll TJ, Riek S, Carson RG (2002) The sites of neural adaptation induced by resistance training in humans. J Physiol 544:641-652

Carroll TJ, Selvanayagam VS, Riek S, Semmler JG (2011) Neural adaptations to strength training: moving beyond TMS and reflex studies. Acta Physiol (Oxf) 202(2):119-140

Cavallari P, Fournier E, Katz R, Malmgren K, Pierrot-Deseilligny E, Shindo M (1985) Cutaneous facilitation of transmission in $\mathrm{Ib}$ reflex pathways in the human upper limb. Exp Brain Res 60:197-199

Chen XY, Chen Y, Wang Y, Thompson A, Carp JS, Segal RL, Wolpaw JR (2010) Reflex conditioning: a new strategy for improving motor function after spinal cord injury. Ann NY Acad Sci 1198 Suppl 1: E12-21

Christie A, Kamen G (2010) Short-term training adaptations in maximal motor unit firing rates and afterhyperpolarization duration. Muscle Nerve 41:651-660

Collins DF (2007) Central contributions to contractions evoked by tetanic neuromuscular electrical stimulation. Exerc Sport Sci Rev 35:102-109

Collins DF, Burke D, Gandevia SC (2002) Sustained contractions produced by plateau-like behaviour in human motoneurones. J Physiol 538:289-301

Colson SS, Martin A, Van Hoecke J (2009) Effects of electromyostimulation versus voluntary isometric training on elbow flexor muscle strength. J Electromyogr Kinesiol 19:311-319

Costa A, Dalloul H, Hegyesi H, Apor P, Csende Z, Racz L, Vaczi M, Tihanyi J (2007) Impact of repeated bouts of eccentric exercise on myogenic gene expression. Eur J Appl Physiol 101:427-436

de Haan A, Gerrits KHL, de Ruiter CJ (2009) Counterpoint: the interpolated twitch does not provide a valid measure of the voluntary activation of muscle. J Appl Physiol 107:355-357

Del Balso C, Cafarelli E (2007) Adaptations in the activation of human skeletal muscle induced by short-term isometric resistance training. J Appl Physiol 103:402-411

Dragert K, Zehr EP (2011) Bilateral neuromuscular plasticity from unilateral training of the ankle dorsiflexors. Exp Brain Res 208:217-227

Duchateau J, Hainaut K (1988) Training effects of sub-maximal electrostimulation in a human muscle. Med Sci Sports Exerc 20:99-104

Duclay J, Martin A, Robbe A, Pousson M (2008) Spinal reflex plasticity during maximal dynamic contractions after eccentric training. Med Sci Sports Exerc 40:722-734

Enoka RM (1988) Muscle strength and its development. New perspectives. Sports Med 6:146-168
Enoka RM (2006) Neuromuscular electrical stimulation: what is activated? In: Rainoldi A, Minetto MA, Merletti R (eds) Biomedical engineering in exercise and sports. Edizioni Minerva Medica, Torino, pp 181-186

Eriksson E, Haggmark T, Kiessling KH, Karlsson J (1981) Effect of electrical stimulation on human skeletal muscle. Int J Sports Med 2:18-22

Everaert DG, Thompson AK, Chong SL, Stein RB (2010) Does functional electrical stimulation for foot drop strengthen corticospinal connections? Neurorehabil Neural Repair 24: $168-177$

Farina D, Holobar A, Merletti R, Enoka RM (2010) Decoding the neural drive to muscles from the surface electromyogram. Clin Neurophysiol 121:1616-1623

Farthing JP (2009) Cross-education of strength depends on limb dominance: implications for theory and application. Exerc Sport Sci Rev 37:179-187

Farthing JP, Krentz JR, Magnus CRA, Barss TS, Lanovaz JL, Cummine J, Esopenko C, Sarty GE, Borowsky R (2011) Changes in fMRI cortical activation with cross-education to an immobilized limb. Med Sci Sports Exerc (in press)

Fimland MS, Helgerud J, Solstad GM, Iversen VM, Leivseth G, Hoff J (2009) Neural adaptations underlying cross-education after unilateral strength training. Eur J Appl Physiol 107:723-730

Fitzgerald GK, Delitto A (2006) Neuromuscular electrical stimualtion for muscle strength training. In: Rainoldi A, Minetto MA, Merletti R (eds) Biomedical engineering in exercise and sports. Edizioni Minerva Medica, Torino, pp 199-207

Francis S, Lin X, Aboushoushah S, White TP, Phillips M, Bowtell R, Constantinescu CS (2009) fMRI analysis of active, passive and electrically stimulated ankle dorsiflexion. Neuroimage 44:469-479

Gabriel DA, Kamen G, Frost G (2006) Neural adaptations to resistive exercise: mechanisms and recommendations for training practices. Sports Med 36:133-149

Glinsky J, Harvey L, van Es P, Chee S, Gandevia SC (2009) The addition of electrical stimulation to progressive resistance training does not enhance the wrist strength of people with tetraplegia: a randomized controlled trial. Clin Rehabil 23: 696-704

Golaszewski SM, Bergmann J, Christova M, Nardone R, Kronbichler M, Rafolt D, Gallasch E, Staffen W, Ladurner G, Beisteiner R (2010) Increased motor cortical excitability after whole-hand electrical stimulation: a TMS study. Clin Neurophysiol 121: $248-254$

Gondin J, Guette M, Ballay Y, Martin A (2005) Electromyostimulation training effects on neural drive and muscle architecture. Med Sci Sports Exerc 37:1291-1299

Gondin J, Duclay J, Martin A (2006) Soleus- and gastrocnemiievoked V-wave responses increase after neuromuscular electrical stimulation training. J Neurophysiol 95:3328-3335

Gondin J, Brocca L, Bellinzona E, D'Antona G, Maffiuletti NA, Miotti D, Pellegrino MA, Bottinelli R (2011) Neuromuscular electrical stimulation training induces atypical adaptations of the human skeletal muscle phenotype: a functional and proteomic analysis. J Appl Physiol 110:433-450

Gregory CM, Bickel CS (2005) Recruitment patterns in human skeletal muscle during electrical stimulation. Phys Ther $85: 358-364$

Gruber M, Taube W, Gollhofer A, Beck S, Amtage F, Schubert M (2007) Training-specific adaptations of $\mathrm{H}$ - and stretch reflexes in human soleus muscle. J Mot Behav 39:68-78

Han BS, Jang SH, Chang Y, Byun WM, Lim SK, Kang DS (2003) Functional magnetic resonance image finding of cortical activation by neuromuscular electrical stimulation on wrist extensor muscles. Am J Phys Med Rehabil 82:17-20 
Hortobágyi T, DeVita P (2000) Favorable neuromuscular and cardiovascular responses to 7 days of exercise with an eccentric overload in elderly women. J Gerontol A Biol Sci Med Sci 55:B401-B410

Hortobágyi T, Lambert J, Scott K (1998) Incomplete muscle activation after training with electromyostimulation. Can J Appl Physiol 23:261-270

Hortobágyi T, Scott K, Lambert J, Hamilton G, Tracy J (1999) Crosseducation of muscle strength is greater with stimulated than voluntary contractions. Mot Control 3:205-219

Hortobágyi T, Devita P, Money J, Barrier J (2001) Effects of standard and eccentric overload strength training in young women. Med Sci Sports Exerc 33:1206-1212

Hortobágyi T, Taylor JL, Russell G, Petersen N, Gandevia SC (2003) Changes in segmental and motor cortical output with contralateral muscle contractions and altered sensory inputs in humans. J Neurophysiol 90:2451-2459

Hortobágyi T, Richardson SP, Lomarev M, Shamim E, Meunier S, Russman H, Dang N, Hallett M (2009) Chronic low-frequency rTMS of primary motor cortex diminishes exercise traininginduced gains in maximal voluntary force in humans. J Appl Physiol 106:403-411

Hortobágyi T, Richardson SP, Lomarev M, Shamim E, Meunier S, Russman H, Dang N, Hallett M (2011) Interhemispheric plasticity in humans. Med Sci Sports Exerc (in press)

Howard JD, Enoka RM (1991) Maximum bilateral contractions are modified by neurally mediated interlimb effects. J Appl Physiol 70:306-316

Huang LP, Zhou S, Lu Z, Tian Q, Li X, Cao LJ, Yu JH, Wang H (2007) Bilateral effect of unilateral electroacupuncture on muscle strength. J Altern Complement Med 13:539-546

Jarvis JC, Mokrusch T, Kwende MM, Sutherland H, Salmons S (1996) Fast-to-slow transformation in stimulated rat muscle. Muscle Nerve 19:1469-1475

Jubeau M, Zory R, Gondin J, Martin A, Maffiuletti NA (2006) Late neural adaptations to electrostimulation resistance training of the plantar flexor muscles. Eur J Appl Physiol 98:202-211

Jubeau M, Gondin J, Martin A, Van Hoecke J, Maffiuletti NA (2010) Differences in twitch potentiation between voluntary and stimulated quadriceps contractions of equal intensity. Scand J Med Sci Sports 20:56-62

Kaelin-Lang A, Luft AR, Sawaki L, Burstein AH, Sohn YH, Cohen LG (2002) Modulation of human corticomotor excitability by somatosensory input. J Physiol 540:623-633

Kendall TL, Black CD, Elder CP, Gorgey A, Dudley GA (2006) Determining the extent of neural activation during maximal effort. Med Sci Sports Exerc 38:1470-1475

Kent-Braun JA, Le Blanc R (1996) Quantitation of central activation failure during maximal voluntary contractions in humans. Muscle Nerve 19:861-869

Khaslavskaia S, Sinkjaer T (2005) Motor cortex excitability following repetitive electrical stimulation of the common peroneal nerve depends on the voluntary drive. Exp Brain Res 162:497-502

Kim CK, Takala TE, Seger J, Karpakka J (1995) Training effects of electrically induced dynamic contractions in human quadriceps muscle. Aviat Space Environ Med 66:251-255

Kimberley TJ, Lewis SM, Auerbach EJ, Dorsey LL, Lojovich JM, Carey JR (2004) Electrical stimulation driving functional improvements and cortical changes in subjects with stroke. Exp Brain Res 154:450-460

Klakowicz PM, Baldwin ER, Collins DF (2006) Contribution of $\mathrm{M}$-waves and $\mathrm{H}$-reflexes to contractions evoked by tetanic nerve stimulation in humans. J Neurophysiol 96:1293-1302

Klass M, Baudry S, Duchateau J (2007) Voluntary activation during maximal contraction with advancing age: a brief review. Eur J Appl Physiol 100:543-551
Lagerquist O, Zehr EP, Docherty D (2006) Increased spinal reflex excitability is not associated with neural plasticity underlying the cross-education effect. J Appl Physiol 100:83-90

Langzam E, Nemirovsky Y, Isakov E, Mizrahi J (2006) Partition between volitional and induced forces in electrically augmented dynamic isometric muscle contractions. IEEE Trans Neural Syst Rehabil Eng 14:322-335

Langzam E, Nemirovsky Y, Isakov E, Mizrahi J (2007) Muscle enhancement using closed-loop electrical stimulation: volitional versus induced torque. J Electromyogr Kinesiol 17:275-284

Lee M, Hinder MR, Gandevia SC, Carroll TJ (2010) The ipsilateral motor cortex contributes to cross-limb transfer of performance gains after ballistic motor practice. J Physiol 588:201-212

Lieber RL, Silva PD, Daniel DM (1996) Equal effectiveness of electrical and volitional strength training for quadriceps femoris muscles after anterior cruciate ligament surgery. J Orthop Res $14: 131-138$

Lloyd T, De Domenico G, Strauss GR, Singer K (1986) A review of the use of electro-motor stimulation in human muscles. Aust J Physiother 32:18-30

Maffiuletti NA (2010) Physiological and methodological considerations for the use of neuromuscular electrical stimulation. Eur J Appl Physiol 110:223-234

Maffiuletti NA, Pensini M, Martin A (2002) Activation of human plantar flexor muscles increases after electromyostimulation training. J Appl Physiol 92:1383-1392

Maffiuletti NA, Pensini M, Scaglioni G, Ferri A, Ballay Y, Martin A (2003) Effect of electromyostimulation training on soleus and gastrocnemii $\mathrm{H}-$ and T-reflex properties. Eur J Appl Physiol 90:601-607

Martin L, Cometti G, Pousson M, Morlon B (1993) Effect of electrical stimulation training on the contractile characteristics of the triceps surae muscle. Eur J Appl Physiol Occup Physiol 67:457-461

Martin L, Cometti G, Pousson M, Morlon B (1994) The influence of electrostimulation on mechanical and morphological characteristics of the triceps surae. J Sports Sci 12:377-381

McMiken DF, Todd-Smith M, Thompson C (1983) Strengthening of human quadriceps muscles by cutaneous electrical stimulation. Scand J Rehabil Med 15:25-28

Merton P (1954) Voluntary strength and muscle fatigue. J Physiol 123:553-564

Nudo RJ, Plautz EJ, Frost SB (2001) Role of adaptive plasticity in recovery of function after damage to motor cortex. Muscle Nerve 24:1000-1019

Nuhr M, Crevenna R, Gohlsch B, Bittner C, Pleiner J, Wiesinger G, Fialka-Moser V, Quittan M, Pette D (2003) Functional and biochemical properties of chronically stimulated human skeletal muscle. Eur J Appl Physiol 89:202-208

Ogino M, Shiba N, Maeda T, Iwasa K, Tagawa Y, Matsuo S, Nishimura H, Yamamoto T, Nagata K, Basford JR (2002) MRI quantification of muscle activity after volitional exercise and neuromuscular electrical stimulation. Am J Phys Med Rehabil $81: 446-451$

Paillard T, Noe F, Passelergue P, Dupui P (2005) Electrical stimulation superimposed onto voluntary muscular contraction. Sports Med 35:951-966

Paillard T, Margnes E, Maitre J, Chaubet V, Francois Y, Jully JL, Gonzalez G, Borel L (2010) Electrical stimulation superimposed onto voluntary muscular contraction reduces deterioration of both postural control and quadriceps femoris muscle strength. Neuroscience 165:1471-1475

Perez M, Lucia A, Rivero JL, Serrano AL, Calbet JA, Delgado MA, Chicharro JL (2002) Effects of transcutaneous short-term electrical stimulation on M.vastus lateralis characteristics of healthy young men. Pflugers Arch 443:866-874 
Perot C, Goubel F, Mora I (1991) Quantification of T- and $\mathrm{H}$-responses before and after a period of endurance training. Eur J Appl Physiol Occup Physiol 63:368-375

Pette D, Vrbova G (1992) Adaptation of mammalian skeletal muscle fibers to chronic electrical stimulation. Rev Physiol Biochem Pharmacol 120:115-202

Pichon F, Chatard JC, Martin A, Cometti G (1995) Electrical stimulation and swimming performance. Med Sci Sports Exerc 27:1671-1676

Pierrot-Deseilligny E, Bussel B, Sideri G, Cathala HP, Castaigne P (1973) Effect of voluntary contraction on $\mathrm{H}$ reflex changes induced by cutaneous stimulation in normal man. Electroencephalogr Clin Neurophysiol 34:185-192

Pierrot-Deseilligny E, Bergego C, Katz R, Morin C (1981) Cutaneous depression of Ib reflex pathways to motoneurones in man. Exp Brain Res 42:351-361

Popovic MR, Curt A, Keller T, Dietz V (2001) Functional electrical stimulation for grasping and walking: indications and limitations. Spinal Cord 39:403-412

Ridding MC, Brouwer B, Miles TS, Pitcher JB, Thompson PD (2000) Changes in muscle responses to stimulation of the motor cortex induced by peripheral nerve stimulation in human subjects. Exp Brain Res 131:135-143

Ridding MC, McKay DR, Thompson PD, Miles TS (2001) Changes in corticomotor representations induced by prolonged peripheral nerve stimulation in humans. Clin Neurophysiol 112:1461-1469

Robinson KL, McIlwain JS, Hayes KC (1979) Effects of H-reflex conditioning upon the contralateral alpha motoneuron pool. Electroencephalogr Clin Neurophysiol 46:65-71

Ruther CL, Golden CL, Harris RT, Dudley GA (1995) Hypertrophy, resistance training, and the nature of skeletal muscle activation. J Strength Cond Res 9:155-159

Sale DG (1988) Neural adaptation to resistance training. Med Sci Sports Exerc 20:S135-S145

Scaglioni G, Ferri A, Minetti AE, Martin A, Van Hoecke J, Capodaglio P, Sartorio A, Narici MV (2002) Plantar flexor activation capacity and $\mathrm{H}$ reflex in older adults: adaptations to strength training. J Appl Physiol 92:2292-2302

Schiaffino S, Gorza L, Sartore S, Saggin L, Ausoni S, Vianello M, Gundersen K, Lomo T (1989) Three myosin heavy chain isoforms in type 2 skeletal muscle fibres. J Muscle Res Cell Motil 10:197-205

Scott OM, Vrbova G, Hyde SA, Dubowitz V (1985) Effects of chronic low frequency electrical stimulation on normal human tibialis anterior muscle. J Neurol Neurosurg Psychiatry 48:774-781

Smith GV, Alon G, Roys SR, Gullapalli RP (2003) Functional MRI determination of a dose-response relationship to lower extremity neuromuscular electrical stimulation in healthy subjects. Exp Brain Res 150:33-39
St Pierre D, Taylor AW, Lavoie M, Sellers W, Kots YM (1986) Effects of 2,500 Hz sinusoidal current on fibre area and strength of the quadriceps femoris. J Sports Med Phys Fitness 26:60-66

Stein RB, Everaert DG, Thompson AK, Chong SL, Whittaker M, Robertson J, Kuether G (2010) Long-term therapeutic and orthotic effects of a foot drop stimulator on walking performance in progressive and nonprogressive neurological disorders. Neurorehabil Neural Repair 24:152-167

Stevens JE, Mizner RL, Snyder-Mackler L (2004) Neuromuscular electrical stimulation for quadriceps muscle strengthening after bilateral total knee arthroplasty: a case series. J Orthop Sports Phys Ther 34:21-29

Stevenson SW, Dudley GA (2001) Dietary creatine supplementation and muscular adaptation to resistive overload. Med Sci Sports Exerc 33:1304-1310

Tamaki T, Uchiyama S, Uchiyama Y, Akatsuka A, Yoshimura S, Roy RR, Edgerton VR (2000) Limited myogenic response to a single bout of weight-lifting exercise in old rats. Am J Physiol Cell Physiol 278:C1143-C1152

Taube W, Kullmann N, Leukel C, Kurz O, Amtage F, Gollhofer A (2007) Differential reflex adaptations following sensorimotor and strength training in young elite athletes. Int J Sports Med 28:999-1005

Taylor J (2009) The interpolated twitch does provide a valid measure of the voluntary activation of muscle. J Appl Physiol 107:354-358

Theriault R, Boulay MR, Theriault G, Simoneau JA (1996) Electrical stimulation-induced changes in performance and fiber type proportion of human knee extensor muscles. Eur J Appl Physiol Occup Physiol 74:311-317

Thorstensson A, Hulten B, von Dobeln W, Karlsson J (1976) Effect of strength training on enzyme activities and fibre characteristics in human skeletal muscle. Acta Physiol Scand 96:392-398

Trimble MH, Enoka RM (1991) Mechanisms underlying the training effects associated with neuromuscular electrical stimulation. Phys Ther 71:273-280; discussion 280-282

Vanderthommen M, Duteil S, Wary C, Raynaud JS, Leroy-Willig A, Crielaard JM, Carlier PG (2003) A comparison of voluntary and electrically induced contractions by interleaved $1 \mathrm{H}-$ and $31 \mathrm{P}-$ NMRS in humans. J Appl Physiol 94:1012-1024

Voigt M, Chelli F, Frigo C (1998) Changes in the excitability of soleus muscle short latency stretch reflexes during human hopping after 4 weeks of hopping training. Eur J Appl Physiol Occup Physiol 78:522-532

Wolpaw JR (2007) Spinal cord plasticity in acquisition and maintenance of motor skills. Acta Physiol (Oxf) 189:155-169

Zehr PE (2002) Considerations for use of the Hoffmann reflex in exercise studies. Eur J Appl Physiol 86:455-468

Zhou S (2000) Chronic neural adaptations to unilateral exercise: mechanisms of cross education. Exerc Sport Sci Rev 28:177-184 